\title{
Evidence that human blastomere cleavage is under unique cell cycle control
}

\author{
Ann A. Kiessling • Ritsa Bletsa • Bryan Desmarais • \\ Christina Mara • Kostas Kallianidis • Dimitris Loutradis
}

Received: 20 December 2008 / Accepted: 16 February 2009/Published online: 14 March 2009

(C) The Author(s) 2009. This article is published with open access at Springerlink.com

\begin{abstract}
Purpose To understand the molecular pathways that control early human embryo development.

Methods Improved methods of linear amplification of mRNAs and whole human genome microarray analyses were utilized to characterize gene expression in normal appearing 8-Cell human embryos, in comparison with published microarrays of human fibroblasts and pluripotent stem cells.

Results Many genes involved in circadian rhythm and cell division were over-expressed in the 8-Cells. The cell cycle checkpoints, RB and WEE1, were silent on the 8-Cell arrays, whereas the recently described tumor suppressor, UHRF2, was up-regulated $>10$-fold, and the protooncogene, MYC, and the core element of circadian rhythm, CLOCK, were elevated up to $>50$-fold on the 8-Cell arrays. Conclusions The canonical G1 and G2 cell cycle checkpoints are not active in totipotent human blastomeres, perhaps replaced by UHRF2, MYC, and intracellular circadian pathways, which may play important roles in early human development.
\end{abstract}

Capsule Evidence that the cell cycle of 8-Cell human blastomeres is growth factor independent and controlled by an intracellular circadian oscillator.

Electronic supplementary material The online version of this article (doi:10.1007/s10815-009-9306-x) contains supplementary material, which is available to authorized users.

A. A. Kiessling $\cdot$ R. Bletsa $\cdot$ C. Mara $\cdot$ K. Kallianidis $\cdot$

D. Loutradis

Department of Obstetrics and Gynecology,

Athens Medical School, "Alexandra” Maternity Hospital,

Athens, Greece

A. A. Kiessling $(\bowtie) \cdot$ B. Desmarais

Bedford Stem Cell Research Foundation,

Somerville, MA 02144, USA

e-mail: kiessling@bedfordresearch.org
Keywords Human embryo · Totipotent · Human blastomere - Cell cycle · Circadian oscillators - CLOCK . Growth factor independent - Retinoblastoma gene $\cdot$ Myc . UHRF2

\section{Introduction}

Fertilization reprograms the human egg and sperm from nondividing, fully differentiated cells into totipotent, cleaving blastomeres. Totipotency persists for three or four cell doublings, from the single cell zygote to the 8- to16-cell morula. The morula traps one or two cells inside, giving rise to an inner group of cells (the inner cell mass, ICM) and an outer layer of trophoblast cells [1]. Once the embryo has reached the 32- to 64-cell stage, the trophoblast cells pump water and nutrients into the interior of the ball, forming a blastocyst, within which the ICM cells continue to proliferate. It is at the blastocyst stage that ICM cells are harvested for the derivation of embryonic stem (ES) cells [2, 3].

Early cleavage divisions are supported by proteins and messenger RNAs stockpiled in the egg, with new gene expression detected at the four- to eight-cell stage in the human [4]. Hence, the 8-Cell embryo is a unique totipotent stage in the human, beginning to guide its own development. For survival, it must quickly give rise to the critical mass of healthy cells needed to signal the mother that it is developing; failure to do so results in menses within a few days. The totipotent 8-Cell may therefore function independent of outside stimuli, and be enriched for cell cycle and chromosome replication machinery that are designed for perfection.

Characterizing gene expression in normal human blastomeres will begin to reveal pathways essential to totipotency, as well as provide guidelines to distinguish viable from non- 
viable embryos to improve outcomes of assisted reproduction. Such information will also provide reference standards for eggs activated artificially to generate parthenote stem cells for therapeutic purposes [5-7]. Ethical considerations surrounding human embryo research necessitate experimental approaches that are accurate with extremely small quantities of starting material. We have taken advantage of newly developed methods for linear amplification of small quantities of mRNA [8] and improved whole human genome microarrays [9-11] to characterize gene expression in two groups of five human 8-cell embryos judged morphologically and by rate of cleavage to be normal and free of fragmentation. We report here the results for the gene elements involved in circadian rhythm and cell division, in comparison with the same analyses previously published for human embryonic stem (hES) cells [12], and human fibroblasts before and after induced pluripotency [13].

\section{Methods and materials}

Embryos and RNA extraction Supernumerary embryos were donated by Greek couples undergoing assisted reproduction in the Department of Obstetrics and Gynecology, Athens Medical School, "Alexandra" Maternity Hospital, Athens, Greece. Because Alexandra Hospital has never had a program of embryo cryopreservation, and because Greek law limits embryos transferred to three per cycle, patients undergoing assisted reproduction receive minimal hormone stimulation, but nonetheless occasionally produce more than three normally cleaving embryos, which are routinely transferred to the patient at the four-cell stage, approximately $72 \mathrm{~h}$ after egg collection, and culture in Universal IVF medium (Medicult). The research protocol to utilize normal-appearing embryos, in excess of the three chosen for transfer, was reviewed and approved by the Institutional Review Boards of Alexandra Hospital and the Bedford Research Foundation.

Pilot studies with mouse embryos revealed that linear amplification for microarray analysis was most reproducibly achieved with purified RNAs from no fewer than 20 embryos. Since a human embryo is approximately four times the size of mouse, and to avoid individual embryo variations, we collected and amplified RNAs from two pools of five human embryos each, judged morphologically and by rate of cleavage to be normal. The two pools of five embryos, fertilized by intracytoplasmic sperm injection and cultured one additional day after the embryo transfer, were donated by nine couples, one couple donated one embryo to each pool, seven of the couples achieved a pregnancy. Embryos were transferred individually to $0.5 \mathrm{~mL}$ flip-top conical tubes in $2 \mathrm{uL}$ of culture medium, flash frozen in liquid nitrogen, and shipped in liquid nitrogen dry shippers to the Bedford Research Foundation laboratory for RNA extraction, ampli- fication and microarray analysis. Embryos were visualized with a dissecting microscope during the thaw process and transferred immediately into $10 \mathrm{uL}$ of Arcturus PicoPure extraction buffer. RNA was isolated and DNAse treated according to manufacture's instructions. RNA isolation in parallel from 20 frozen mouse embryos was analyzed in an Agilent Bioanalyzer and found to have $28 \mathrm{~S}$ to $18 \mathrm{~S}$ RNA peak ratios of 1.8 to 2.0 .

Antisense mRNA amplification 8-Cell mRNAs were amplified according to a protocol previously reported to be linear for RNAs from 10 human eggs [8] and linear in pilot studies from 20 mouse embryos. Briefly, step one was reverse transcription in the presence of T4 Gene Protein with RNAse H-free MuLV using an oligo-dT [24] primer linked to T7 RNA polymerase binding site, in the presence of a second SMART IIA primer with polyG at the 3' end to bind in the opposite orientation to the polyC 3' end created by MuLV RT Powerscript, which then completes the strand extension. Step two was twenty cycles of PCR with Smart primers -1 and -2 in the PCR Advantage kit with polymerase AD2; amplified cDNAs were purified from the PCR reaction with Qiagen PCR Clean-up kit. Antisense cRNAs were amplified from the purified cDNAs by $\mathrm{T} 7$ in an overnight reaction, followed by purification with Arcturus PicoPure and analysis on the Agilent Bioanalyzer to verify amplification of cRNAs in the $7 \mathrm{~S}$ to $10 \mathrm{~S}$ size range.

Microarray analyses cRNAs were shipped to MoGene (St. Louis, MO) for Cy3-labelling (Kreatech Kit) and overnight hybridization to Agilent whole human genome, $44 \mathrm{~K}$ microarray. Mouse embryo RNAs amplified and analyzed in parallel as controls were hybridized to the Agilent $44 \mathrm{~K}$ mouse development array. Hybridization intensities were normalized by Agilent Feature Extraction Software. RTPCR verification revealed complete agreement with the microarrays, in keeping with results reported by the MicroArray Quality Control (MAQC) Project [11].

Normalized fluorescent intensities (fluorescence units, FUs) were imported into a FileMaker Pro database containing tables of published data (GEO, NCBI) for the same Agilent microarray analysis of human fibroblasts, human iPS cells [13], and two human ES cell lines, H9 and hES0 [12]. Gene elements were aligned by matching unique Agilent probe numbers. The combined database containing six datasets was used to determine statistical parameters for over - and under- expression, as well as comparison of patterns of gene expression among the 4 cell types. We first assessed differences between the two 8-Cell arrays to estimate differences in RNA amplification linearity between the embryo pools. The sums of FUs (184,359,915, 8-CellA; 195,617,837, 8-CellB) were similar, ratio 1.06. The average ratio for FUs for each of the $44 \mathrm{~K}$ 
gene elements on the 8-Cell arrays was $1.0 \pm 3.0$. The sums of FUs for the hES cell arrays were also similar to each other $(123,522,149$, hES01; 139,596,169, H9; ratio 1.1). The average ratio of FUs for each gene element on the hES arrays was also 1.0, but the standard deviation was only \pm 0.2 . The sums of FUs for the fibroblast and iPS cell arrays were lower $(117,920,961$, fibros; $88,483,505$, iPS). Comparing individual gene elements, the average ratio of 8-Cell FUs to hES FUs for each gene element was $19 \pm 371$, and an even greater difference for 8-Cells relative to fibroblasts, $65 \pm 1005$, well beyond the variation between the replicate data sets.

We also examined the relative fluorescence of four common RT-PCR reference genes: ACTB, GADPH, RPLP0, UBC. The ratio of 8-Cell A to 8-Cell B varied from 0.6 (ACTB) to 2.4 (UBC), possibly reflecting variation in mRNA amplification, although the ratio of the average 8-Cell signal to the average hES cell signal was within a similar range, 0.2 (GADPH) to 2.4 (RPLP0). Taken together, the six array data sets were in good agreement for commonly expressed genes, as reported [11]. We reasoned, therefore, that for the purpose of the analyses presented here, ratios \pm 7 -fold ( 2 standard deviations from the mean ratio of the 8-cell array elements multiplied by the overall 1.5 higher total 8-Cell array signal) are well outside array fluctuations and probably biologically relevant.

The lists of gene elements involved in circadian rhythmn (Table 1), cell cycle regulation (Tables $\mathrm{S} 2$ and 2), and chromosome duplication (Tables S3 and 2) were compiled by comparing GO terms (www.geneontology.org), KEGG (www.genome.ad.jp/kegg) and Reactome (www.reactome. org) pathways, DAVID 2008 (david.abcc.ncifcrf.gov), and hand annotated for accuracy.

\section{Results}

Overview of array Almost half of the gene elements detected above threshold level were common to all four cell types, the highest signal intensities of which $(1,030$ elements, Table S1, bedfordresearch.org/supplement) were enriched for GO terms related to ribonucleoprotein, RNA processing and protein processing. Of the remainder, the 8Cell arrays exhibited differential expression of gene elements involved in circadian rhythm and cell division.

Circadian clock Most gene elements of the core intracellular circadian oscillator were over-expressed on the 8-Cell arrays, including CLOCK, detected up to 56-fold higher on the 8-Cell arrays than the hES arrays, and Period (PER 1,-2,-3), detected up to 45 -fold higher on the 8-Cells arrays (Table 1).

Cell cycle Of the 138 genes (210 gene elements) on the microarrays directly involved in regulation of the cell cycle, $81(57 \%)$ were detected within \pm 7 -fold FUs on all six microarrays (Table S2, bedfordresearch.org/supplement). Four gene elements, CDK6, E2F3, RB1 and WEE1, were silent only on the 8-Cell arrays (Tables S2). In contrast, AURKC, CCNA1 and CCNB3 were detected above threshold levels specifically on the 8-Cell arrays, with

Table 1 Circadian rhythm gene elements

\begin{tabular}{|c|c|c|c|c|c|c|c|c|c|c|c|}
\hline Agilent probe & $\begin{array}{l}\text { Gene } \\
\text { symbol }\end{array}$ & 8 CellA* & 8CellB* & $\begin{array}{l}\text { Entrez } \\
\text { gene } \\
\text { ID** }\end{array}$ & $\begin{array}{l}\text { Fibro- } \\
\text { blasts* }\end{array}$ & iPS* & hES01* & H9ES* & $\begin{array}{l}\text { 8Cell/ } \\
\text { hES**** }\end{array}$ & $\begin{array}{l}\text { 8Cell/ } \\
\text { Fibro }\end{array}$ & $\begin{array}{l}\text { Genbank } \\
\text { accession }\end{array}$ \\
\hline A_23_P162037 & $\begin{array}{l}\text { ARNTL } \\
\text { (BMAL1) }\end{array}$ & 988.0 & 682.4 & 406 & 432.3 & 635.3 & 421.3 & 301.9 & 2.3 & 1.9 & NM_001178 \\
\hline A_23_P419038 & CLOCK & 7710.0 & 12065.0 & 9575 & 213.5 & 142.1 & 191.1 & 164.1 & 55.7 & 46.3 & NM_004898 \\
\hline A_24_P166168 & CLOCK & 1020.0 & 2668.8 & 9575 & 335.4 & 275.0 & 295.6 & 238.6 & 6.9 & 5.5 & AK096319 \\
\hline A_24_P407235 & CRY1 & 291.0 & 1285.0 & 1407 & 119.0 & 182.1 & 224.8 & 257.6 & 3.3 & 6.6 & NM_004075 \\
\hline A_23_P36665 & CRY1 & 1700.0 & 4520.9 & 1407 & 365.2 & 643.6 & 683.2 & 735.7 & 4.4 & 8.5 & NM_004075 \\
\hline A_23_P388027 & CRY2 & 685.0 & 687.3 & 1408 & 12.4 & 11.6 & 33.2 & 35.6 & 20.0 & 55.2 & NM_021117 \\
\hline A_24_P158587 & CRY2 & 237.0 & 259.3 & 1408 & 55.9 & 49.1 & 115.1 & 111.2 & 2.2 & 4.4 & NM_021117 \\
\hline A_23_P127394 & CRY2 & 1300.0 & 2257.6 & 1408 & 791.9 & 940.2 & 1420.9 & 1976.2 & 1.0 & 2.2 & NM_021117 \\
\hline A_24_P93916 & PER1 & 145.0 & 231.3 & 5187 & 6.2 & 3.2 & 11.0 & 9.5 & 18.4 & 30.3 & NM_021724 \\
\hline A_23_P89589 & PER1 & 949.0 & 5227.0 & 5187 & 344.5 & 609.4 & 971.7 & 1010.7 & 3.1 & 9.0 & ВС028207 \\
\hline A_23_P411162 & PER2 & 652.0 & 1652.0 & 8864 & 11.5 & 7.1 & 24.4 & 27.1 & 44.8 & 100.4 & NM_022817 \\
\hline A_23_P209320 & PER2 & 801.0 & 2699.8 & 8864 & 203.7 & 172.0 & 312.0 & 395.2 & 5.0 & 8.6 & NM_022817 \\
\hline A_24_P230948 & PER3 & 84.9 & 890.7 & 8863 & 23.0 & 14.8 & 12.9 & 36.2 & 19.9 & 21.2 & NM_016831 \\
\hline A_23_P201461 & PER3 & 488.0 & 512.6 & 8863 & 58.8 & 27.5 & 47.9 & 65.0 & 8.9 & 8.5 & NM_016831 \\
\hline
\end{tabular}

*Values are processed signal fluorescence units (FUs); fibro and iPS from [13]; hES from [12] 
Table 2 Gene elements elevated on 8-cell arrays

\begin{tabular}{|c|c|c|c|c|c|c|c|c|c|}
\hline $\begin{array}{l}\text { Gene } \\
\text { symbol* }\end{array}$ & 8CellA** & 8CellB** & $\begin{array}{l}\text { Entrez } \\
\text { GeneID }\end{array}$ & $\begin{array}{l}\text { Fibro- } \\
\text { blasts** }\end{array}$ & $\begin{array}{l}\text { iPS } \\
\text { cells } * *\end{array}$ & hES01** & H9ES** & $\begin{array}{l}\text { 8Cell/ } \\
\text { hES }\end{array}$ & $\begin{array}{l}\text { 8Cell/ } \\
\text { Fibro }\end{array}$ \\
\hline \multicolumn{10}{|c|}{ Cell cycle gene elements } \\
\hline AURKA & 20800.0 & 71812.6 & 6790 & 1521.7 & 3233.7 & 5225.0 & 6338.3 & 8.0 & 37.3 \\
\hline AURKB & 13500.0 & 7485.3 & 9212 & 136.4 & 955.7 & 798.1 & 966.4 & 11.9 & 76.9 \\
\hline AURKC & 24600.0 & 12799.8 & 6795 & 13.5 & 42.9 & 107.5 & 85.6 & 193.7 & 1385.2 \\
\hline CCNA1 & 32400.0 & 28099.2 & 8900 & 3.0 & 149.6 & 85.9 & 74.9 & 376.2 & 10083.2 \\
\hline CCNB1 & 161000.0 & 151796.2 & 891 & 4003.7 & 13791.9 & 19416.6 & 18960.5 & 8.1 & 33.6 \\
\hline CCNB3 & 3100.0 & 2491.0 & 85417 & 26.0 & 16.0 & 26.6 & 19.6 & 121.0 & 107.5 \\
\hline CCNE1 & 115000.0 & 90920.9 & 898 & 1596.4 & 8037.0 & 12575.4 & 13491.6 & 7.9 & 64.5 \\
\hline CCNG2 & 1030.0 & 1397.4 & 901 & 412.2 & 97.2 & 68.0 & 72.9 & 17.2 & 2.9 \\
\hline CDC25B & 28408.3 & 28200.0 & 994 & 4449.0 & 538.3 & 887.1 & 1234.3 & 26.7 & 6.4 \\
\hline CDKN1A & 1510.0 & 4258.5 & 1026 & 27718.3 & 498.5 & 750.9 & 445.0 & 4.8 & 0.1 \\
\hline CDKN1A & 1090.0 & 1066.9 & 1026 & 1232.8 & 79.2 & 44.0 & 31.0 & 28.8 & 0.9 \\
\hline MYC & 27280.9 & 24600.0 & 4609 & 3297.5 & 4033.7 & 5704.0 & 4470.7 & 5.1 & 7.9 \\
\hline MYC & 11401.8 & 1390.0 & 4609 & 82.5 & 81.8 & 401.9 & 384.8 & 16.3 & 77.5 \\
\hline MYC & 1565.3 & 1450.0 & 4609 & 6.8 & 12.8 & 25.6 & 23.3 & 61.7 & 221.7 \\
\hline UHRF1 & 11000.0 & 13033.8 & 29128 & 75.0 & 176.9 & 326.8 & 251.1 & 41.6 & 160.2 \\
\hline UHRF1 & 15700.0 & 62284.0 & 29128 & 1090.2 & 1082.8 & 4078.1 & 3090.0 & 10.9 & 35.8 \\
\hline UHRF2 & 8490.0 & 13844.1 & 115426 & 1941.6 & 823.0 & 1712.7 & 2602.1 & 5.2 & 5.8 \\
\hline UHRF2 & 3890.0 & 4946.6 & 115426 & 714.7 & 277.9 & 344.7 & 464.5 & 10.9 & 6.2 \\
\hline \multicolumn{10}{|c|}{ Chromosome duplication gene elements } \\
\hline GINS3 & 28800.0 & 13693.3 & 64785 & 793.3 & 1851.8 & 5057.2 & 4059.7 & 4.7 & 26.8 \\
\hline GINS3 & 6500.0 & 1213.2 & 64785 & 28.7 & 79.4 & 249.0 & 203.3 & 17.1 & 134.4 \\
\hline GINS4 & 5970.0 & 5842.8 & 84296 & 387.6 & 2093.4 & 215.4 & 228.0 & 26.6 & 15.2 \\
\hline GINS4 & 2890.0 & 3265.3 & 84296 & 73.2 & 493.4 & 65.2 & 103.4 & 36.5 & 42.0 \\
\hline POLS & 16400.0 & 31321.7 & 11044 & 1220.1 & 892.5 & 1047.8 & 1471.3 & 18.9 & 19.6 \\
\hline PTMS & 291000.0 & 83326.5 & 5763 & 5116.9 & 1659.1 & 8936.4 & 20535.0 & 12.7 & 36.6 \\
\hline PTTG1 & 594610.3 & 564000.0 & 9232 & 15479.5 & 31030.4 & 41398.3 & 49470.2 & 12.8 & 37.4 \\
\hline PTTG1IP & 11788.1 & 7140.0 & 754 & 1471.9 & 405.9 & 684.7 & 671.6 & 14.0 & 6.4 \\
\hline PTTG2 & 267263.5 & 302000.0 & 10744 & 3151.4 & 5635.2 & 6024.5 & 6083.0 & 47.0 & 90.3 \\
\hline PTTG3 & 29941.2 & 19300.0 & 26255 & 285.6 & 663.9 & 674.1 & 808.6 & 33.2 & 86.2 \\
\hline STAG3 & 50200.0 & 110926.9 & 10734 & 138.4 & 1080.9 & 1077.4 & 717.1 & 89.8 & 582.1 \\
\hline STAG3L3 & 54500.0 & 24701.3 & 442578 & 493.7 & 908.9 & 690.0 & 522.0 & 65.3 & 80.2 \\
\hline
\end{tabular}

*Values are processed fluorescence units; fibroblasts and iPS from [13]; hES cells from [12]

AURKA and -B at least 8-fold higher on the 8-Cell arrays (Table S2, Table 2). Cyclins A1, $-\mathrm{B} 3,-\mathrm{E} 1$, - and $-\mathrm{G} 2$ were detected at much higher levels on the $8 \mathrm{C}$ arrays, as was the kinase inhibitor, $\operatorname{CDKN} 1 \mathrm{~A}(\mathrm{p} 21)$, and the kinase activator, CDC25A, each detected over 26-fold higher on the 8-cell arrays (Tables 2 and S2). UHRFI, known to downregulate RB1 [14], was detected up to 42-fold higher on the 8-Cell arrays than the hES cell arrays (Tables S2 and 2). UHRF2 (NIRF) [15], detected up to 11-fold higher on the 8-Cell arrays than the hES cell arrays, is capable of blocking G1 progression [16] independent of RB.

Chromosome duplication Of the 126 genes (189 gene probes) on the microarrays directly involved in DNA replication (Table
S3), 96 (76\%) exhibited \pm 7 -fold FUs on all arrays. Gene elements essential for the initiation of DNA replication [17], ORCs, CDC6, CDT1 and MCMs, were detected on the gene arrays of all four cell types at approximately equivalent levels (Table S3). The four members of the GINS complex, essential for both the initiation and extension of DNA replication [18-21] are the most over-expressed on the 8-Cell arrays (up to 37-fold higher than hES cells) and the most underexpressed in the fibroblasts (Table S3 and 2).

Parathymosin (PTMS), a highly conserved nuclear protein, was detected 13-fold higher on the 8-Cell arrays than the hES arrays and 37-fold higher than the fibroblast arrays (Tables S3 and 2). DNA polymerase sigma (POLS, also DNA polymerase kappa), thought to be involved in 
DNA strand synthesis around cohesin sites, was detected at 20 -fold higher levels on the 8-Cell arrays. Two members of cohesin, STAG3 and STAG3L3, were detected $>65$-fold higher on the 8-Cell arrays (Tables 2 and S3).

\section{Discussion}

Circadian clock The circadian clock is an elegantly simple network, highly conserved from bacteria to man, of transcriptional and translational feedback loops that complete one cycle approximately every $24 \mathrm{~h}$ [22-24], perhaps to ensure DNA synthesis during the night to avoid ultraviolet light-induced damage [25]. The core mammalian pacemaker is comprised of the transcription factors CLOCK, ARNTL(BMAL1), Period (PER1, -2, -3) and Cryptochrome (CRY1,-2). CLOCK and ARNTL form a heterodimer that binds to the E-box elements of PER(s) and CRY(s) to stimulate their expression. Upon reaching a critical concentration, PER/CRY heterodimers inhibit CLOCK/ARNTL, thus leading to a decrease in their own expression. The decrease in PER/CRY allows resumption of CLOCK/ARNTL stimulation of PERs and CRYs, thus repeating the cycle. Mutations in CLOCK have revealed that NPAS2 can at least partially substitute for CLOCK to regulate PER/CRY expression. CLOCK/NPAS2/ARNTL is considered the positive branch of the loop, and PER/CRY the negative branch of the loop.

An estimated $5 \%$ to $10 \%$ of genes exhibit expression with a circadian pattern $[26,27]$, some of which augment the core pacemaker, but by definition, elimination or mutation of core elements alters or extinguishes the rhythm [28]. In addition to the gene elements whose expression cycles when the pacemaker is functioning, there is a growing list of genes that do not cycle, but whose expression is influenced by the clock [26, 27]. There is increasing evidence that the pacemaker is active in all cells, and that genes regulated by the clock are cell and tissue specific key pathway elements, such as the circadian expression of heme and factor VII by the liver [29, 30]. Individual fibroblasts maintain their circadian rhythm for up to two weeks in culture $[31,32]$. CLOCK also has histone acetyltransferase activity, providing a new clue to the breadth of its transcriptional regulation activity [33].

Period (PER1,-2,-3), the first circadian gene identified in Drosophila [34] and recently described in early zebrafish embryos [35] was detected up to 52-fold higher on the 8Cell arrays relative to other cells. The onset of Per expression following fertilization of zebrafish eggs establishes an autonomous circadian rhythm in zebrafish embryo cells that entrains a number of pathways, including DNA synthesis.
Cell cycle An essential feature of the cell cycle is that it proceeds in one direction, to ensure one, and only one, complete replication of chromosomes, enforced by stage specific kinases activated and/or suppressed at key points in the cycle $[17,36]$. Important kinase activators are the cyclins, whose expression rises and falls with each cell cycle stage. Cyclins form heterodimers with specific kinases, generally to activate them and define their substrates, but sometimes to suppress their activity. Cell cycle kinase inhibitors, such as CDKN1A(p21), and checkpoint proteins, such as Rb and Wee1, block cell cycle progression, presumably to ensure that critical, stage specific steps are completed.

Cyclin D (CCND) expression is generally stimulated by growth factors to start progression through Gap1 (G1) of the cell cycle; it combines with CDK4 (or CDK6) to phosphorylate a number of proteins, including inactivation of $\mathrm{RB}$, leading to expression of $\mathrm{E} 2 \mathrm{~F}$ transcription factorregulated genes such as Cyclin $E$, needed for the $\mathrm{G} 1 / \mathrm{S}$ transition. That the lack of RB expression could render cells immortalized without growth factor stimulation was demonstrated by knocking out RB in mouse fibroblasts, which eliminated the G1 checkpoint, allowing cell growth without growth factors [37]. The relative expression of CCND1, -2 , and -3 varies widely among different cell types, including those reported here (Table S2); however, all three appear to be necessary for normal progression of G1 [38].

UHRF1 (ubiquitin PHD RING Finger family member 1, ICBP90) and UHRF2 (NIRF) are members of a newly described tumor suppressor family [15], known to down regulate $\mathrm{Rb}$ [16]. Generally, cyclin $\mathrm{D} / \mathrm{CDK} 4 / 6$ neutralizes $\mathrm{RB}$ allowing expression of cyclin $\mathrm{E}$ (CCNE), an activator of Cdk2. CDK4 was detected at approximately the same levels in all microarrays, but as previously noted, CDK6 was silent on the 8-Cell arrays. CCNE1 and -2 were detected at nearly an order of magnitude higher on the 8 Cell arrays (Tables S2 and 2), perhaps due to the absence of RB. Activation of cyclinE/Cdk2 leads to $\mathrm{G} 1$ to $\mathrm{S}$ transition, a block to which may be brought about by UHRF2 [16], thus possibly providing an alternate to the RB block to $\mathrm{G} 1 / \mathrm{S}$ transition.

MYC, a well studied oncogene that also encodes an E-box element transcription factor, has been reported to stimulate $\mathrm{G} 1$ to $\mathrm{S}$ transition by a parallel pathway that functions somewhat independent of E2F-induced transcription, although both MYC and E2F are required for normal cell cycles [39]. CDKN1A is a key negative regulator of cell cycle kinases that displays a circadian pattern of expression in mouse muscle and liver [27], and is also negatively regulated by MYC [40]. These considerations suggest the growth factor/CCND/RB paradigm of most cells may be replaced by CCND/UHRF2/MYC/CDKN1A in the 8-Cells. 
$S$ Phase Activated CCNE/CDK2 indces the expression of cyclin A (CCNA), necessary to initiate DNA replication. Both CCNA1 and -2 were detected on the 8-Cell arrays, but only CCNA2 was detected on all other arrays, although at 10-fold lower levels than the 8-cell arrays. CCNA2 is essential for post-blastocyst mouse embryo development [41]. It binds $\mathrm{Cdk} 2$ during $\mathrm{S}$ phase and $\mathrm{Cdk} 1(\mathrm{Cdc} 2)$ during G2. Dephosphorylation of $\mathrm{Cdk} 2$ by $\mathrm{Cdc} 25 \mathrm{~A}$ is required to activate cyclinA/Cdk2 in S phase [42]. In the mouse, CCNA1 is expressed in the testis, not the ovary [43] and is required for the progression of male, but not female, germ cells through the first meiotic division. In contrast, human CCNA1 is not only expressed in the testis, but in several types of leukemic cells, in which it inhibits apoptosis [44]. In frog embryos, cyclinA1 predominates from fertilization through gastrulation, and combines only with $\mathrm{Cdk} 2$, not $\mathrm{Cdk} 1$, suggesting it does not play a role in stimulating $\mathrm{S}$ phase, but only in entry to mitosis, and supports apoptosis of frog embryo cells that have accumulated DNA damage [45].

The ORC-MCM complex is joined by the GINS complex (Sld5, Psf1, Psf2, Psf3, or 5-1-2-3 which, in Japanese, is 'Go-Ichi-Ni-San'), essential for both the initiation and extension of DNA replication [18-21]. Interestingly, the GINS elements are also up-regulated in the iPS cells relative to fibroblasts (Table 2), supporting their beneficial, but unknown, role in pluripotency.

PTMS has been localized to DNA replication forks [46], in association with glucocorticoid response elements [47], and shown to compete with histone $\mathrm{H} 1$, resulting in chromatin remodeling [48], suggesting an enhanced role in both DNA replication and transcription in the 8-Cells.

PolA/primase initiates DNA strand replication, and PolD, a more processive enzyme that elongates strands, were detected at similar levels in all four cell types (Table S3).

Pols is a link between DNA replication and the establishment, and maintenance, of cohesion sites during chromosome duplication [49]. One thought is that cohesions, tightly bound to chromatin, require the action of a specially adapted DNA polymerase to continue strand synthesis. Replication may proceed via PolD to a cohesion site, at which point polymerase switching occurs and PolS continues strand elongation through the cohesion site. Cohesin is a complex of proteins that includes STAG3 and STAG3L3 thought to be established in part by the replication machinery and essential for accurate chromosome duplication [49, 50].

Cyclin G2 (CCNG2) is an atypical cyclin that does not bind to a cyclin-dependent kinase, and is generally associated with cell cycle arrest, particularly in response to DNA damage [51]. It associates with centrosomes, so perhaps its role in the 8-Cells is to ensure accurate and timely centrosome replication.
G2 phase The transition from $\mathrm{S}$ phase to $\mathrm{G} 2$ phase involves cyclinA/cdk1 (cdc2) activity, completion of DNA replication, nucleosome reformation and the beginning of centrosome replication. CyclinA still bound to $\mathrm{cdk} 2$ also plays a role in progression through $\mathrm{G} 2$ by coordinating cyclinB/cdk1 activity at the centrosomes and in the nucleus [42]. Pituitary tumortransforming gene (PTTG) and its binding protein (PTTG1IP) are involved in multiple cell functions, including delaying the onset of mitosis for DNA repair, and stabilizing sister chromatid association as a securin that binds and inactivates separase for most of the cell cycle [52]. The intronless variants, PTTG2 and PTTG3, are expressed in a variety of tissues, but their function is unknown.

The G2/M transition is coordinated by cyclinB (CCNB) replacing cyclin $\mathrm{A}$ in association with $\mathrm{Cdk} 1$. It may be significant that CCNB1 levels correlated with increased pluripotency, being lowest in the fibroblasts, higher in the iPS cells, and highest in the 8-Cells (Tables S3 and 2). Cyclin B3, a recently identified, unusually large cyclin detected in human testis [53], at lower levels in other tissues during all phases of the cell cycle, was detected only on the 8-Cell arrays (Tables S2 and 2). The function of CCNB3 is unknown; it binds to but does not activate Cdk2, suggesting it may play a negative regulatory role [54]. Recent evidence suggests that in addition to other roles, CDC25B, the phosphatase that activates Cdk1, plays an important role in synchronizing centrosome duplication to mitosis [55].

WEE1, a key G2 phase cell cycle regulator, silent on the 8-Cell arrays, has a circadian pattern of expression in both muscle and liver of the mouse [27], in addition to which, expression is negatively regulated by TBPL1 [56], detected 19-fold higher on the 8-Cell arrays (Table S3).

Mitosis The Aurora kinases, A, B and C are highly conserved serine/threonine protein kinases that have important regulatory roles during cell division. Aurora A is central to mitotic spindle organization; Aurora $\mathrm{B}$ is localized to centromeres from anaphase to telophase, phosphorylates Histone $\mathrm{H} 3$ during mitosis, and remains associated with the spindle midzone where the contractile ring forms [57]. Aurora C co-localizes with Aurora B during the cell cycle, and may play a similar function and prior to this report was found predominantly in the testis [58].

Once spindle alignment of chromosomes passes the spindle checkpoint, the orderly progression through mitosis is principally regulated by degradation of proteins in sequence. First cyclinA, followed by cyclinB and securin, which releases separase to degrade cohesin allowing sisterchromatid separation. Each of these elements was detected on the 8-Cell arrays at levels equal to or greater than the other cell types, suggesting the 8-Cell demonstrates robust 
expression of proteins important to accurate chromosome duplication and division.

Conclusions These findings indicate that $\mathrm{RB}$ is silenced in the 8-Cells, perhaps by UHRF1, and that the G1 checkpoint generally imposed by RB may be at least partially replaced by UHRF2. WEE1 is suppressed in the 8-Cells, perhaps by TBPL1, and the G2 checkpoint generally imposed by Wee1 may be replaced by Plk1 whose activation in G2 by Pak1 may be controlled by the circadian expression of CDKN1A, which is also under MYC control. The silence of both RB and WEE1, along with up-regulation of UHRF, MYC, CCNA1, PTTG, AURC and PLK1 may be markers of totipotency.

The silence of RB and WEE1 in the 8-Cells was a surprise, but supports the concept that early, totipotent blastomeres do not depend on outside stimuli to overcome a G1 block, and other mechanisms, such as enhanced expression of cohesin proteins, ensure accurate DNA replication and spindle arrangement of chromosomes during G2. More details of these mechanisms will become available when the expression profile of transcription and translation factors on these arrays are analyzed.

There are significant potential pitfalls in drawing conclusions about gene function from microarray analyses, especially those in which the mRNAs have been enzymatically amplified, even if that has been demonstrated to be linear. Certainly mRNA expression does not accurately predict protein abundance or activity, but several lines of evidence suggest the major differences in levels of array fluorescence for the key cell cycle gene elements described in this report reflect unique cell cycle controls in the totipotent 8-Cell embryos. A recent report [59] that miRNA-34a down regulates CDK6, CCNE2 and E2F3, provides a provocative explanation that miRNA-34a in the 8-Cells accounts for the low or absent detection of CDK6, CCNE2 (but not CCNE1), and E2F3, but not the other E2Fs (Tables S2 and 2). The detection of CCNA1, CCNB3 and AURKC only on the 8-Cell arrays is not likely due to artificial loss from the other arrays because the results were reproducible between two laboratories on two continents. A similar argument holds for the circadian clock genes, the expression of which by the 8-Cells supports growing evidence that circadian control of gene expression needs to be more widely appreciated in the design of culture conditions for embryos.

Acknowledgements We wish to thank Ryan Kiessling for database organization and assistance with array analysis. This work was supported by the Bedford Research Foundation, Naylor Fund for Stem Cell Research, and special account (vat\#090145420) for research grants of the National and Kapodistian University of Athens.
Open Access This article is distributed under the terms of the Creative Commons Attribution Noncommercial License which permits any noncommercial use, distribution, and reproduction in any medium, provided the original author(s) and source are credited.

\section{References}

1. Kiessling AA, Davis HW, Williams CS, Sauter RW, Harrison LW. Development and DNA polymerase activities in cultured preimplantation mouse embryos: comparison with embryos developed in vivo. J Exp Zool. 1991;258(1):34-47. doi:10.1002/jez. 1402580105 .

2. Reubinoff BE, Pera MF, Fong CY, Trounson A, Bongso A. Embryonic stem cell lines from human blastocysts: somatic differentiation in vitro. Nat Biotechnol. 2000;18(4):399-404. doi:10.1038/74447.

3. Thomson JA, Itskovitz-Eldor J, Shapiro SS, Waknitz MA, Swiergiel JJ, Marshall VS, et al. Embryonic stem cell lines derived from human blastocysts. Science. 1998;282(5931):11457. doi:10.1126/science.282.5391.1145.

4. Braude P, Bolton V, Moore S. Human gene expression first occurs between the four- and eight-cell stages of preimplantation development. (Translated from eng). Nature. 1988;332(6163):459 61. in eng. doi:10.1038/332459a0

5. Kiessling AA. Eggs alone. Nature. 2005;434(7030):145. doi:10.1038/434145a.

6. Polak de Fried E, Ross P, Zang G, Divita A, Cunniff K, Denaday F, et al. Human parthenogenetic blastocysts derived from noninseminated cryopreserved human oocytes. Fertil Steril. 2007;89(4): 943-7.

7. Revazova ES, Turovets NA, Kochetkova OD, Kindarova LB, Kuzmichev LN, Janus JD, et al. Patient-specific stem cell lines derived from human parthenogenetic blastocysts. Cloning Stem Cells. 2007;9(3):432-49.

8. Kocabas AM, Crosby J, Ross PJ, Otu HH, Beyhan Z, Can H, et al. The transcriptome of human oocytes. Proc Natl Acad Sci USA. 2006;103(38):14027-32. doi:10.1073/pnas.0603227103.

9. Canales RD, Luo Y, Willey JC, Austermiller B, Barbacioru CC, Boysen C, et al. Evaluation of DNA microarray results with quantitative gene expression platforms. Nat Biotechnol. 2006;24 (9):1115-22. doi:10.1038/nbt1236.

10. Morey JS, Ryan JC, Van Dolah FM. Microarray validation: factors influencing correlation between oligonucleotide microarrays and real-time PCR. Biol Proced Online. 2006;8:175-93. doi:10.1251/ bpo126.

11. Shi L, Reid LH, Jones WD, Shippy R, Warrington JA, Baker SC, et al. The microarray quality control (MAQC) project shows inter- and intraplatform reproducibility of gene expression measurements. Nat Biotechnol. 2006;24(9):1151-61. doi:10.1038/nbt1239.

12. Tesar P, Chenoweth JG, Brook FA, Davies TJ, Evans EP, Mack $\mathrm{DL}$, et al. New cell lines from mouse epiblast share defining features with human embryonic stem cells. Nature. 2007;448 (7150):196-9. doi:10.1038/nature05972.

13. Takahashi K, Tanabe K, Ohnuki M, Narita M, Ichisaka T, Tomoda $\mathrm{K}$, et al. Induction of pluripotent stem cells from adult human fibroblasts by defined factors. Cell. 2007;131(5):861-72. doi:10.1016/j.cell.2007.11.019.

14. Jeanblanc M, Mousli M, Hopfner R, Bathami K, Martinet N, Abbady AQ, et al. The retinoblastoma gene and its product are targeted by ICBP90: a key mechanism in the G1/S transition during the cell cycle. Oncogene. 2005;24(49):7337-45. doi:10.1038/sj.onc.1208878. 
15. Bronner C, Achour M, Arima Y, Chataigneau T, Saya H, SchiniKerth VB, et al. The UHRF family: oncogenes that are drugable targets for cancer therapy in the near future? Pharmacol Ther. 2007;115(3):419-34. doi:10.1016/j.pharmthera.2007.06.003.

16. Li Y, Mori T, Hata H, Homma Y, Kochi H. NIRF induces G1 arrest and associates with Cdk2. Biochem Biophys Res Commun. 2004;319(2):464-8. doi:10.1016/j.bbrc.2004.04.190.

17. DePamphilis ML. Cell cycle dependent regulation of the origin recognition complex. Cell Cycle. 2005;4(1):70-9.

18. Choi JM, Lim HS, Kim JJ, Song OK, Cho Y. Crystal structure of the human GINS complex. Genes Dev. 2007;21(11):1316-21. doi:10.1101/gad.1548107.

19. Labib K, Gambus A. A key role for the GINS complex at DNA replication forks. Trends Cell Biol. 2007;17(6):271-8. doi:10.1016/j.tcb.2007.04.002.

20. Chang YP, Wang G, Bermudez V, Hurwitz J, Chen XS. Crystal structure of the GINS complex and functional insights into its role in DNA replication. Proc Natl Acad Sci USA. 2007;104 (31):12685-90. doi:10.1073/pnas.0705558104.

21. Kamada K, Kubota Y, Arata T, Shindo Y, Hanaoka F. Structure of the human GINS complex and its assembly and functional interface in replication initiation. Nat Struct Mol Biol. 2007;14 (5):388-96. doi:10.1038/nsmb1231.

22. Dunlap JC. Molecular bases for circadian clocks. Cell. 1999;96 (2):271-90. doi:10.1016/S0092-8674(00) 80566-8.

23. Ko CH \& Takahashi JS (2006) Molecular components of the mammalian circadian clock. Hum Mol Genet 15 Spec No 2:R271277.

24. Mackey SR. (2007) Biological Rhythms Workshop IA: molecular Basis of Rhythms Generation. Clocks and Rhythms, (Cold Spring Harbor Press), pp 7-20

25. Ozturk N, Song SH, Ozgür S, Selby CP, Morrison L, Partch C, et al. (2007) Structure and Function of Animal Cryptochromes. Clocks and Rhythms, (Cold Spring Harbor Press), 72:119-31

26. McCarthy JJ, Andrews JL, McDearmon EL, Campbell KS, Barber $\mathrm{BK}$, Miller BH, et al. Identification of the circadian transcriptome in adult mouse skeletal muscle. Physiol Genomics. 2007;31 (1):86-95. doi:10.1152/physiolgenomics.00066.2007.

27. Miller BH, McDearmon EL, Panda S, Hayes KR, Zhang J, Andrews JL, et al. Circadian and CLOCK-controlled regulation of the mouse transcriptome and cell proliferation. Proc Natl Acad Sci USA. 2007;104(9):3342-7. doi:10.1073/pnas.0611724104.

28. Takahashi JS. Finding new clock components: past and future. J Biol Rhythms. 2004;19(5):339-47. doi:10.1177/ 0748730404269151.

29. Bertolucci C, Cavallari N, Colognesi I, Aguzzi J, Chen Z, Caruso $\mathrm{P}$, et al. Evidence for an overlapping role of CLOCK and NPAS2 transcription factors in liver circadian oscillators. Mol Cell Biol. 2008;28(9):3070-5. doi:10.1128/MCB.01931-07.

30. Zheng B, Albrecht U, Kaasik K, Sage M, Lu W, Vaishnav S, et al. Nonredundant roles of the mPer1 and mPer2 genes in the mammalian circadian clock. Cell. 2001;105(5):683-94. doi:10.1016/S0092-8674(01) 00380-4.

31. Welsh DK, Yoo SH, Liu AC, Takahashi JS, Kay SA. Bioluminescence imaging of individual fibroblasts reveals persistent, independently phased circadian rhythms of clock gene expression. Curr Biol. 2004;14(24):2289-95. doi:10.1016/ j.cub.2004.11.057.

32. Yoo SH, Yamazaki S, Lowrey PL, Shimomura K, Ko CH, Buhr ED, et al. PERIOD2:LUCIFERASE real-time reporting of circadian dynamics reveals persistent circadian oscillations in mouse peripheral tissues. Proc Natl Acad Sci USA. 2004;101 (15):5339-46. doi:10.1073/pnas.0308709101.
33. Belden WJ, Loros JJ, Dunlap JC. CLOCK leaves its mark on histones. Trends Biochem Sci. 2006;31(11):610-3. doi:10.1016/j. tibs.2006.09.009.

34. Bargiello TA, Young MW. Molecular genetics of a biological clock in Drosophila. Proc Natl Acad Sci USA. 1984;81(7):21426. doi:10.1073/pnas.81.7.2142.

35. Dekens MP, Whitmore D. Autonomous onset of the circadian clock in the zebrafish embryo. EMBO J. 2008;27(20):2757-65. doi:10.1038/emboj.2008.183.

36. Yu H. Cdc20: a WD40 activator for a cell cycle degradation machine. Mol Cell. 2007;27(1):3-16. doi:10.1016/j.molcel.2007. 06.009 .

37. Sage J, Mulligan GJ, Attardi LD, Miller A, Chen S, Williams B, et al. Targeted disruption of the three Rb-related genes leads to loss of G(1) control and immortalization. Genes Dev. 2000;14 (23):3037-50. doi:10.1101/gad.843200.

38. Bartkova J, Lukas J, Strauss M, Bartek J. Cyclin D3: requirement for $\mathrm{G} 1 / \mathrm{S}$ transition and high abundance in quiescent tissues suggest a dual role in proliferation and differentiation. Oncogene. 1998;17(8):1027-37. doi:10.1038/sj.onc.1202016.

39. Santoni-Rugiu E, Falck J, Mailand N, Bartek J, Lukas J. Involvement of Myc activity in a G(1)/S-promoting mechanism parallel to the pRb/E2F pathway. Mol Cell Biol. 2000;20 (10):3497-509. doi:10.1128/MCB.20.10.3497-3509.2000.

40. Jung P, Menssen A, Mayr D, Hermeking H. AP4 encodes a cMYC-inducible repressor of p21. Proc Natl Acad Sci USA. 2008;105(39):15046-51. doi:10.1073/pnas.0801773105.

41. Murphy M, Stinnakre MG, Senamaud-Beaufort C, Winston NJ, Sweeney C, Kubelka M, et al. Delayed early embryonic lethality following disruption of the murine cyclin A2 gene. Nat Genet. 1997;15(1):83-6. doi:10.1038/ng0197-83.

42. De Boer L, Oakes V, Beamish H, Giles N, Stevens F, Somodevilla-Torres $\mathrm{M}$, et al. Cyclin A/cdk2 coordinates centrosomal and nuclear mitotic events. Oncogene. 2008;27(31):42618. doi:10.1038/onc.2008.74.

43. Persson JL, Zhang Q, Wang XY, Ravnik SE, Muhlrad S, Wolgemuth DJ, et al. Distinct roles for the mammalian A-type cyclins during oogenesis. Reproduction. 2005;130(4):411-22. doi:10.1530/rep. 1.00719.

44. Ji P, Bäumer N, Yin T, Diederichs S, Zhang F, Beger C, et al. DNA damage response involves modulation of $\mathrm{Ku} 70$ and $\mathrm{Rb}$ functions by cyclin A1 in leukemia cells. Int J Cancer. 2007;121 (4):706-13. doi:10.1002/ijc.22634.

45. Carter AD, Wroble BN, Sible JC. Cyclin A1/Cdk2 is sufficient but not required for the induction of apoptosis in early Xenopus laevis embryos. Cell Cycle. 2006;5(19):2230-6.

46. Vareli K, Frangou-Lazaridis M, van der Kraan I, Tsolas O, van Driel R. Nuclear distribution of prothymosin alpha and parathymosin: evidence that prothymosin alpha is associated with RNA synthesis processing and parathymosin with early DNA replication. Exp Cell Res. 2000;257(1):152-61. doi:10.1006/excr. 2000.4857.

47. Okamoto K, Isohashi F. Macromolecular translocation inhibitor II $(\mathrm{Zn}(2+)$-binding protein, parathymosin) interacts with the glucocorticoid receptor and enhances transcription in vivo. J Biol Chem. 2005;280(44):36986-93. doi:10.1074/jbc.M5060 56200.

48. Martic G, Karetsou Z, Kefala K, Politou AS, Clapier CR, Straub T, et al. Parathymosin affects the binding of linker histone H1 to nucleosomes and remodels chromatin structure. J Biol Chem. 2005;280(16):16143-50. doi:10.1074/jbc.M410175200.

49. Carson DR, Christman MF. Evidence that replication fork components catalyze establishment of cohesion between sister 
chromatids. Proc Natl Acad Sci USA. 2001;98(15):8270-5. doi:10.1073/pnas.131022798.

50. Liu J, Krantz ID. Cohesin and human disease. Annu Rev Genomics Hum Genet. 2008;9:303-20. doi:10.1146/annurev. genom.9.081307.164211.

51. Arachchige Don AS, Dallapiazza RF, Bennin DA, Brake T, Cowan CE, Horne MC, et al. Cyclin G2 is a centrosome-associated nucleocytoplasmic shuttling protein that influences microtubule stability and induces a p53-dependent cell cycle arrest. Exp Cell Res. 2006;312(20):4181-204. doi:10.1016/j.yexcr.2006.09.023.

52. Vlotides G, Eigler T, Melmed S. Pituitary tumor-transforming gene: physiology and implications for tumorigenesis. Endocr Rev. 2007;28(2):165-86. doi:10.1210/er.2006-0042.

53. Lozano JC, Perret E, Schatt P, Arnould C, Peaucellier G, Picard A, et al. Molecular cloning, gene localization, and structure of human cyclin B3. Biochem Biophys Res Commun. 2002;291(2):406-13. doi:10.1006/bbrc.2002.6458.

54. Tschop K, Muller GA, Grosche J, Engeland K. Human cyclin B3. mRNA expression during the cell cycle and identification of three novel nonclassical nuclear localization signals. FEBS J. 2006;273 (8):1681-95. doi:10.1111/j.1742-4658.2006.05184.x.

55. Boutros R, Ducommun B. Asymmetric localization of the CDC25B phosphatase to the mother centrosome during interphase. Cell Cycle. 2008;7(3):401-6.

56. Tanaka Y, Nanba YA, Park KA, Mabuchi T, Suenaga Y, Shiraishi $\mathrm{S}$, et al. Transcriptional repression of the mouse wee1 gene by TBP-related factor 2. Biochem Biophys Res Commun. 2007;352 (1):21-8. doi:10.1016/j.bbrc.2006.10.175.

57. Salaun P, Rannou Y, Prigent C. Cdk1, Plks, Auroras, and Neks: the mitotic bodyguards. Adv Exp Med Biol. 2008;617:41-56. doi:10.1007/978-0-387-69080-3_4.

58. Hu HM, Chuang CK, Lee MJ, Tseng TC, Tang TK. Genomic organization, expression, and chromosome localization of a third aurora-related kinase gene, Aie1. DNA Cell Biol. 2000;19 (11):679-88. doi:10.1089/10445490050199063.

59. Sun F, Fu H, Liu Q, Tie Y, Zhu J, Xing R, et al. Downregulation of CCND1 and CDK6 by miR-34a induces cell cycle arrest. FEBS Lett. 2008;582(10):1564-8. doi:10.1016/j.febslet.2008.03.057. 